mon rooms for the staff, living accommodation for visiting workers and a permanent exhibition room containing demonstrations for visiting fruit-growers. Adjacent to the Institute are a number of apartment houses for the staff, and future plans envisage the addition of an extensive block of experimental glass-houses and cold stores. On one side of the building lies the large experimental orchard of the Warsaw College of Agriculture containing demonstration experiments and an important collection of 1,800 species and varieties of cultivated fruits.

Most of the field experiments of the Institute are carried out at field stations situated in the different fruit-growing regions of the country. In all there are eleven such field stations, varying in size from 140 to 1,440 acres, each under the control of a director and small scientific staff, working in close co-operation with the staff of the Institute. The total area available for such field experiments is about 5,800 acres, of which a considerable proportion is at present devoted to extensive variety trials of tree fruits, currants, gooseberries and strawberries. The chief object of these trials is to find high-yielding varieties of good quality that are capable of surviving the extreme cold of the Polish winter. The trials themselves are well laid out and are randomized and replicated to an extent sufficient to satisfy the most fastidious statistician. In addition to these field stations the Institute has also planted many experimental and demonstration orchards on the State farms, and a few on peasants' holdings.

The creation of the Research Institute is due largely to the enterprise and initiative of the present director, Prof. S. A. Pieniaziek, who returned to Poland from the United States in 1946. One of his chief difficulties throughout has been the acute shortage of trained scientific workers. At the end of the Second World War there were only four persons with Ph.D. degrees working in pomology in Poland : to-day the number has risen to about twenty, but most of the ninety-nine members of the scientific staff of the Institute are recent graduates with relatively liutle research experience. A few have received training in Moscow, and almost all have the ambition to work for a time in
England in order to broaden their experience or to acquire specialist techniques.

The work of the Research Institute is divided into twelve departments designed to cover most of the problems of importance for fruit growing, such as soil cultivation, fruit breeding, mechanization, plant protection, and fruit technology. Winter killing is undoubtedly the most serious problem confronting fruit growers in Poland, and much research effort is devoted to the study of this problem, particularly to methods of increasing winter hardiness of trees and the selection of cold-resistant varieties. The importance of this problem is shown by the violent fluctuations of the fruit tree population during recent years. It is estimated that in 1939 there were about fifty million fruit trees in Poland. More than half of these were destroyed by cold in the winter of 1939-40, and by the end of the War the population had further decreased to twenty-two million. Extensive post-war plantings, which are still continuing, had raised the number to approximately thirty-five million in 1955 ; but a further severe winter during 1955-56 again wrought great havoc, particularly among pears and plums, in the orchards of central Poland.

In the Soviet Union, pomological science, under the influence of Michurin, has developed along lines different from those pursued in Western Europe and Scandinavia, and many concepts basic to Russian pomological work (for example, graft hybridization; the 'mentor' theory) are regarded with scepticism by pomologists in other countries, including, incidentally, many in Poland. Soviet pomologists, on the other hand, are equally sceptical of much Western work, particularly that relating to virus diseases in fruit crops and the application of statistical methods to field experiments. Poland, open to cultural influences from both East and West, is bound to neither school of thought, and the present policy of pomological research is to make use of those ideas and techniques that seem most appropriate to the problems in hand, irrespective of their origins. Here, indeed, in a limited field of endeavour, we have a true hybrid between Eastern and Western scientific thought which, though yet young, already manifests the marked vigour characteristic of crosses between widely dissimilar parents.

\title{
DISLOCATIONS AND THE MECHANICAL PROPERTIES OF CRYSTALS
}

$\mathrm{D}$ URING September 6-1, about forty metallurgists and physicists from various countries met at Lake Placid, New York, to discuss the mechanical properties of dislocated crystals. The conference was sponsored jointly by the U.S. Office of Scientific Research, Air Research and Development Command. and by the General Flectric Research Laboratory, Schenectady, and organized by Dr. J. C. Fisher. The discussions were quite informal and their purpose was to assess, in the light of recent work, the extent to which we understand the mechanical effects of dislocations in crystals. A few related questions were also taken up, such as the growth of whisker crystals and the nature of radiation damage.

Comparing this conference with those held in the United Kingdom in 1954, I was struck by two major changes in the subject, both of which were foreseen at the earlier conferences. First, the study of dislocations has now become very definitely an experimental- ist's subject. By contrast, the development of dislocation theory has, temporarily at least, almost ceased. The reason for this is fairly clear. The geometrical and elastic theories of single dislocations and of simple arrays of dislocations have now been almost completely worked out, and only the very hard problems of the dynamics of fast-moving dislocations and of the detailed atomic structures in the cores of dislocations remain. But to understand workhardening, creep, fatigue, fracture and recrystallization, we have to study the collective behaviour of large, complex assemblies of dislocations, and the theory of this can go forward only when experiments have shown what are the decisive aspects of this behaviour in practice.

The second striking change is that the experimentalists are no longer content to look merely at slip lines. Stimulated mainly by the development of etch-pit techniques and by methods of precipitating 
atoms on the cores of dislocations, they now insist on seeing the individual dislocations in their specimens. As a result, when they now speak about dislocations gliding and multiplying in slip lines, and climbing out of these lines and polygonizing, they are no longer making theoretical conjectures, but are descriking what they have actually seen taking place.

One of the most vivid examples of this was provided by Dr. P. B. Hirsch's motion-picture film of disloca. tions in aluminium foils observed by transmission electron microscopy. Here we were able to see single dislocations gliding, sometimes slowly, sometimes quickly, along close-packed planes. We saw them bow out under applied stress, interact with each other, reach unstable configurations and then run rapidly into nearby sub-boundaries. We also saw how remarkably effective an applied stress can be in breaking up dislocation nets within the crystal and driving the dislocations into boundaries, a fact often inferred previously from results of creep and recovery experiments, but never before actually seen.

It is pleasing to see how many of the predictions of dislocation theory, made a few years ago, are now being confirmed. The study of dislocation networks in ionic crystals, made visible by the precipitation of metallic atoms on the dislocation lines, has gone forward actively, and Dr. S. Amelinckx and Dr. J. W. Mitchell showed many examples of networks, in silver halides, sodium chloride and calcium fluoride, which conformed closely to the patterns expected from considerations of Burgers vectors and elastic stability. Isolated closed dislocation rings and spiral dislocation lines were also seen in the calcium fluoride specimens, so confirming the ideas of Prof. F. Seitz about the condensation of point defects into platelets and on to screw dislocations. We were also shown some beautiful examples of Frank-Read sources in operation in silicon, photographed by Dr. W. C. Dash, using copper atoms to mark the dislocation lines and infra-red light to photograph them.

Drs. J. J. Gilman and W. G. Johnston have developed a versatile etch-pit technique for studying dislocations in lithium fluoride. One type of etchant attacks all types of dislocations in the material, whereas another type attacks only those dislocations that have (presumably) absorbed some impurity during annealing; freshly created dislocations can thus be distinguished from old ones. The symmetry of an etch-pit differs according to whether the dislocation it marks is an edge or a screw, so that these two types of dislocation can be distinguished. When a dislocation is pulled away from its etch-pit, that pit then develops a flat bottom, so that the present and past positions of a dislocation can be identified. Perhaps the most outstanding of the many observations made on lithium fluoride with this technique is that, at a stress of about $1 \mathrm{kgm}$. mm. ${ }^{-2}$, small dislocation loops can nucleate, grow and multiply into fully active slip bands in apparently perfect regions of the crystal. These intriguing results aroused much discussion. It seems clear that here a complete slip band can be formed independently of a dislocation network. One suggestion, made by Dr. W. M. Lomer, is that parts of an expanding dislocation ring may in fact jump from one slip plane to another, by cross-slip, so that segments of dislocation lines capable of acting as Frank-Read sour ces may be formed in the neighbouring slip planes. The nature of the primary defects, from which the first loops are nucleated, remains a mystery. Dr. J. C. Fisher suggested that they may be small platelets of condensed vacancies; but so far it has not been possible to reveal them by etching.

Several experiments were described that gave evidence about the location of the original sources of slip in various crystals. Dr. W. T. Read deduced, from an observation that more dislocations are formed when a germanium crystal is bent than would be expected from the theory of plastic bending, that some. dislocation sources became operative in the interior of the crystal. In a somewhat similar experiment on an aluminium crystal strained in tension, Prof. B. Chalmers deduced, from the character of X-ray reflexions obtained by the Schultz method, that the dislocations must have moved into the crystal from the surface. Further evidence for slip starting at the surface was presented by Dr. T. Suzuki, who worked with potassium chloride, and the present writer, who described some work of Mr. M. A. Adams on copper. Suzulki showed that birefringent bands first appeared on two opposite faces at the beginning of slip, and that the effect of contaminating these faces with impurity caused the yield stress to increase. Adams showed that a copper crystal normally does not yield discontinuously or strain-age, but that it can be made to do so by introducing 1 per cent of zinc into its surface. These effects, which suggest that slip begins at surface sources, disappear when the zincified layer is removed.

Several examples of impurity yield points were reported ; arsenic in copper (1Dr. W. Boas) and oxygen in silicon (Dr. W. T. Read) both produce the effect. Dr. K. Lücke described an extensive investigation of the pinning of dislocations by impurity atorns, based on the damping of high-frequency $\left(10^{8} \mathrm{c} . / \mathrm{s}\right.$. $)$ oscillations. The rates of migration of impurity atoms to dislocations and their binding energies in dislocations were both measured in these experiments; for example, bismuth in lead is bound to dislocations with an energy of $0 \cdot 11 \mathrm{eV}$. Dr. W. Boas showed some effects of impurities on the annealing behaviour of cold-worked copper, which Prof. N. F. Mott interpreted in terms of the anchoring of jogs by impurity atoms, so hindering the climb of dislocations. The rate of climb of dislocations was also discussed by Prof. F. R. N. Nabarro in an analysis of the straightening of kinked whisker crystals.

One point which emerged strongly at the conference is that in many materials dislocations glide rather 'stickily', suggesting that they are hindered by a large Peierls-Nabarro force. We saw examples of this in Gilman's work, in which the stress to move visible dislocations varies sensitively with temperature and rate of strain and always remains large even in apparently perfect regions of the crystal; also in silicon, in which the yield stress is very sensitive to temperature even after the impurity yield point has been overcome (W. T. Read), and in which the dislocation lines follow crystallographic directions closely (W. C. Dash) and take up positions in the slip plane which appear to be determined by their rate of glide rather than by their mutual elastic interactions. Gilman showed that fast-moving cracks (more than $10^{4} \mathrm{~cm}$. sec. ${ }^{-1}$ ) do not produce dislocation loops at their tips, whereas slow ones (less than $10^{4} \mathrm{~cm}$. sec.-1) do. Since large amounts of energy can be dissipated by slip at the tips of cracks, the stickiness or otherwise of dislocations undoubtedly plays a major part in determining the tendency towards brittleness or ductility of crystals. Even in metals, it begins to look as if the Peierls-Nabarro force is small only for slip on close-packed planes. According to Dr. A. 
Seeger, the force does not make itself felt in these planes until rather low temperatures (lower than $100^{\circ} \mathrm{K}$.) are reached, where the internal friction of the metal rises up to the 'Bordoni peak'. In the facecentred cubic rnetals, we scarcely ever see slip on planes other than close-packed ones, except possibly at high temperatures; similarly, in close-packed hexagonal metals, only the basal slip system has a flow stress that is insensitive to temperature, and the high sensitivity of other systems to temperature is strongly suggestive of a large PeierlsNabarro force. It now seems probable that the sensitivity of the yield stress in iron is due at least partly to a large Peierls-Nabarro force, which may help to account partly for some of the observations on delayed yielding in iron that were reported to the conference by Dr. D. s. Wood.

In the discussions of solid-solution hardening and radiation hardening, the point was brought out from the work of Prof. R. W. K. Honeycombe and Dr. T. Blewitt that the yield stress of such materials is quite a sensitive, parabolic, function of temperature. Dr. H. Suzuli offered an explanation of the solid solution case in terms of the impurity yield-point mechanism, and several views were expressed about radiation hardening. Dr. J. Friedel suggested that vacancies agglomerated into large voids along dislocations, Dr. T. Blewitt considered that aggregates of point defects formed in the lattice would produce a type of precipitate hardening, while the present writer explored the possibility that the absorption of point defects by dislocations would cause the latter to climb out of their glide planes and thereby give them a large Peierls-Nabarro force.

The discussions of work-hardening were centred mainly around the nature of the obstacles responsible for work-hardening. Dr. A. Seeger showed that slip dislocations escape from their barriers in the slip planes by undergoing cross-slip and he proposed a variant of the Lomer-Cottrell barrier in which slip dislocations in screw orientation would become locked against barriers formed from two secondary slip systems. Prof. N. F. Mott raised the question of the behaviour of such systems on unloading. It seemed to the writer that the back-stress from its own piledup group of dislocations could not be the reason why a given dislocation source ceased to act during unidirectional straining; for if this were the case, the stored elastic energy in the system would be nearly equal to the total work done, and most of the plastic strain would be recovered during unloading. The hardening of the Frank-Read sources must originate in some other way, perhaps from the internal stresses due to other nearby dislocation groups, as in the theory suggested a few years ago by Prof. Mott.

The problem of understanding fatigue failure still appears very difficult. The idea that vacancies are formed during the glide of dislocations has met with difficulties, mainly because we are still not sure how dislocations can produce vacancies; in fact, when gliding screw dislocations intersect they are more likely, if they produce any point defects at all, to produce interstitials rather than vacancies. Prof. Mott proposed a new mechanism whereby a gliding screw, oscillating to and fro with the applied stress, jumps cvelically from one plane to another by means of cross-slip at the ends of its path; this causes the material between these planes to be squeezed out of the crystal, leaving behind a void in the slipped region. This ought to be just the type of process that could be examined directly by the new experimental techniques mentioned above.

Interest has grown rapidly in recent years in the mobilities of various types of defects in solids, particularly at very low temperatures. Prof. J. S. Koehler, Dr. 'T. Blewitt and Dr. W. Boas summarized recent work on the annealing of point defects in quenched, irradiated and cold-worked metals, and Dr. G. Leibfried concluded that zero-point motion may contribute to the mobility of point defects at very low temperatures, but is unlikely to be important in the motion of dislocations because the vibrational modes useful for helping dislocations over barriers have long wave-lengths and low Debye temperatures. Dr. Rlewitt showed that copper crystals can be work-hardened in liquid helium up to yield stresses greater than one per cent of the elastic constant, and that at these high stresses it is possible to pull partial dislocations away from one another, so forming stacking faults and deformation twins. Prof. C. S. Barrett described some recent work by Dr. P. Haasen and Dr. A. Kelly which showed that nickel and copper crystals develop yield points after plastic straining, unloading and reloading, in liquid helium, and Dr. Blewitt mentioned that internal friction experiments have shown that dislocations can become pinned as a result of neutron irradiation at $17^{\circ} \mathrm{K}$. Certainly, one of the most fascinating developments of the subject in recent years is the discovery of so much evidence for atomic movements in erystals at temperatures of a fow degrees above absolute zero.

A. H. Cottreli.

\section{OBITUARIES}

\section{Mr. H. N. Ridley, C.M.G., F.R.S.}

Mr. H. N. Ridiey died in his one hundred and first year at his home at 7 Cumberland Road, Kew, on October 24. On the occasion of his hundredth birthday (December 10, 1955), Mr. J. W. Purseglove contributed to Nature an appreciation of Ridley's many-sided activities in Singapore and Malaya, and the reader is referred to this for a fuller survey of his life and work.

He was born at West Harling, in Norfolk, son of the Rev. Oliver Matthew Ridley and Louisa Pole (Stuart). He was proud to count among his ancestors Nicholes Ridley (Bishop of London, 1550-55),
William Penn, and the third Earl of Bute, who was botanical adviser to the Princess Augusta, founder of the Royal Botanic Gardens, Kew.

Ridley took all Nature for his province. In his boyhood he was interested mainly in birds and insects; after studying natural science at Oxford he was awarded a scholarship in geology; he came finally to an intensive study of botany almost as an accident when, having failed to obtain a zoological post, he applied in 1880 for a post in the Botany Department of the British Museum (Natural History). In the following eight years he specialized in the study of tropical Monocotyledons, but did not neglect other groups of plants ; and he maintained an active 